Research Paper

\title{
A DNA Vaccine Encoding for TeSSP4 Induces Protection against Acute and Chronic Infection in Experimental Chagas Disease
}

\author{
Minerva Arce-Fonseca1,2, ${ }^{1,}$ Angel Ramos-Ligonio ${ }^{1,3,}{ }^{*}$, Aracely López-Monteón ${ }^{1,3}$, Berenice Salgado- \\ Jiménez ${ }^{1}$, Patricia Talamás-Rohana ${ }^{1}$, and José Luis Rosales-Encina ${ }^{1, \varpi}$
}

1. Departamento de Infectómica y Patogenesis Molecular, Centro de Investigación y de Estudios Avanzados del I.P.N., México D.F. 07360, México

2. Departamento de Biología Molecular, Instituto Nacional de Cardiología “Ignacio Chávez", México D.F.14080, México.

3. LADISER Inmunología y Biología Molecular, Facultad de Ciencias Químicas, Universidad Veracruzana, Orizaba, Veracruz, 94340, México.

* These authors contributed equally to this work.

Corresponding author: José Luis Rosales-Encina. Departamento de Infectómica y Patogénesis Molecular, Centro de Investigación y de Estudios Avanzados del I.P.N., Avenida Instituto Politécnico Nacional No. 2508, Col. San Pedro Zacatenco, Delegación Gustavo A. Madero, México D.F., México. CP 07360. Telephone: (52) 55-5747-3349, Fax (52) 55-5747-3377. E-mail: rosales@cinvestav.mx.

() Ivyspring International Publisher. This is an open-access article distributed under the terms of the Creative Commons License (http://creativecommons.org/ licenses/by-nc-nd/3.0/). Reproduction is permitted for personal, noncommercial use, provided that the article is in whole, unmodified, and properly cited.

Received: 2011.09.01; Accepted: 2011.10.01; Published: 2011.10.25

\begin{abstract}
Immunization of mice with plasmids containing genes of Trypanosoma cruzi induces protective immunity in the murine model of Chagas disease. A cDNA clone that codes for an amastigote-specific surface protein (TCSSP4) was used as a candidate to develop a DNA vaccine. Mice were immunized with the recombinant protein rTcSSP4 and with cDNA for TCSSP4, and challenged with bloodstream trypomastigotes. Immunization with rTCSSP4 protein makes mice more susceptible to trypomastigote infection, with high mortality rates, whereas mice immunized with a eukaryotic expression plasmid containing the TCSSP4 cDNA were able to control the acute phase of infection. Heart tissue of gene-vaccinated animals did not show myocarditis and tissue damage at 365 days following infection, as compared with control animals. INF- $\gamma$ was detected in sera of DNA vaccinated mice shortly after immunization, suggesting the development of a ThI response. The TcSSP4 gene is a promising candidate for the development of an anti-T. cruzi DNA vaccine.
\end{abstract}

Key words: DNA immunization; Trypanosoma cruzi; TcSSP4

\section{Introduction}

Chagas disease caused by Trypanosoma cruzi continues as a major health problem in South and Central America, although the estimated number of infected people has fallen from approximately 20 million in 1981 to around 10 million in 2009 due to the implementation of measures for vector control and safer blood transfusions. The risk of transmission of the disease is high because the infection has been detected in non-endemic areas of the Americas, the
Western Pacific Region, and the European Region [1-4].

The development of anti-T. cruzi vaccines could contribute significantly to controlling transmission of Chagas disease [5]. It has been shown that immunization with plasmids containing $T$. cruzi genes induces immune responses able to protect against lethal infection with $T$. cruzi [5-11]. The immune responses induced by DNA immunization are mediated by anti- 
bodies, $\mathrm{CD}^{+}$, and $\mathrm{CD}^{+} \mathrm{T}$ cells. Th1 cytokines secreted by $\mathrm{CD}^{+} \mathrm{T}$ cells stimulate macrophages' phagocytic activity, B-cell proliferation and antibody production. Additionally, increased cytolysis of parasite-infected cells by $\mathrm{CD}^{+} \mathrm{T}$ cells and secretion of cytokines (INF- $\gamma$ ) that may induce trypanocidal activity have been described [12-14]. The crucial role of CD8+ $\mathrm{T}$ cells to control T. cruzi infection has been demonstrated from studies showing the inability of mice lacking CD8+ T cell to survive infection (15-17), and the ability to increase the level of resistance to infection by boosting CD8+ $\mathrm{T}$ cell responses with strong immunodominant epitopes from the trans-sialidase family [18-21].

To date, DNA immunization protocols against T. cruzi infection have used genes associated with trypomastigotes in experimental models. However, the study and characterization of DNA vaccines from genes expressed by amastigotes, the form that multiplies inside the host cells, have been recently initiated $[10,11]$. We have identified a cDNA clone that codes for an amastigote-specific surface protein (TcSSP4). The recombinant protein MBP::SSP4 was able to induce macrophage nitric oxide production. This recombinant protein was also shown to induce the expression of IL-1a, IL-6, IL-12, IFN- $\gamma$, and TNF- $\alpha$ in macrophages from normal mice, and IL-10 in macrophages from immunized mice, suggesting that TcSSP4 protein could participate in the immunoregulatory process during Chagas' disease [22]. In this work we first analyzed the effect of a single dose of the recombinant protein $r \mathrm{TcSSP} 4$ on the course of parasitemia and survival of trypomastigote infected mice, and then we analyzed the potential of the gene TcSSP4 as a DNA vaccine.

\section{Materials and Methods}

\section{Parasites}

The H8 strain of T. cruzi [A gift from Dr. Jorge E. Zavala Castro, Centro de Investigaciones Regionales "Dr. Hideyo Noguchi", Universidad Autónoma de Yucatán, Mérida, Yucatán, México] was maintained in vivo by serial passages of blood form trypomastigotes in BALB/c mice and by weekly in vitro passages of epimastigotes in Liver Infusion Tryptose (LIT) with 10 $\%$ of fetal calf serum (Gibco, Invitrogen), as described [22].

\section{Plasmid construction and recombinant protein expression and purification}

DNA encoding for the TcSSP4 protein (GeneBank $^{\mathrm{TM}}$ database accession number AF480943) was obtained from the plasmid pMAL-TcSSP4 [22] as a 2.2
Eco RI fragment and ligated in the Eco RI site of plasmids pBk-CMV (Stratagene, La Jolla , CA) and pTWIN1 (New England BioLabs) for construction of DNA vectors pBCSSP4 and pTWSSP4, respectively. The plasmid pTWIN1 was used in order to obtain the recombinant protein TcSSP4 (rTcSSP4) without the MBP tag. Purification of the recombinant protein rTcSSP4 was achieved by transforming the plasmid pTWSSP4 into E. coli BL21(DE3). Cells were grown at $37{ }^{\circ} \mathrm{C}$ to $\mathrm{OD}_{595}=0.5$ and induced with $0.3 \mathrm{mM}$ IPTG for $6 \mathrm{~h}$, then harvested by centrifugation and lysed by sonication in the presence of $10 \mu \mathrm{g} / \mathrm{ml}$ lysozyme. The expressed $r T c S S P 4$ protein was purified from the lysate by using a chitin-affinity column, followed by intein cleavage by temperature shift from $4{ }^{\circ} \mathrm{C}$ to $25^{\circ} \mathrm{C}$ at $\mathrm{pH} 7.0$, according to the manufacturer's protocol. Analysis of protein purification was carried out by 10\% SDS-PAGE and Coomassie blue staining.

\section{Immunization and trypomastigote infection of mice}

Female 6-8-week old BALB/c mice were maintained according to the recommendations of our Institutional Animal Care and Use Committee. For protein immunization, each mouse was immunized i.p. with $10 \mu \mathrm{g}$ of $r \mathrm{TcSSP} 4$ protein emulsified with Freund's complete adjuvant (Sigma, St Louis, MO). DNA immunizations were done twice at 2 week intervals in the tibialis anterioris muscle with the plasmids pBCSSP4 or pBk-CMV resuspended in PBS. Mice immunized with the $r T c S S P 4$ protein were challenged i.p. with $1 \times 10^{4}$ or $3 \times 10^{4}$ bloodstream trypomastigotes (BT) 3 or 7 days post-immunization. Mice immunized with DNA were challenged 2 weeks after the last immunization with $1 \times 10^{4} \mathrm{BT}$. Parasitemia was monitored every 3 days. All mice were randomly assigned into control or vaccinated groups of four mice each in two independent experiments $(n=8)$.

\section{Histopatology}

Hearts from infected mice were removed, rinsed with PBS, and fixed for $24 \mathrm{~h}$ in $4 \%$ paraformaldehyde in PBS (pH 7.4). Fixed hearts were embedded in paraffin, sectioned $(6 \mu \mathrm{m})$, stained with hematoxylin-eosin, and examined by light microscopy (Nikon Eclipse E600, Nikon, Japan).

\section{Serum cytokine analysis}

Sera of mice immunized with DNA or $r$ TcSSP4 protein were collected at 3 and $12 \mathrm{~h}$ after the last immunization. Pools of sera from each group of immunized mice were analyzed for the presence of IL-2, IL-4, IL-6, IL-10, TNF- $\alpha$, and IFN- $\gamma$ with commercially available murine cytokine ELISA kits (OptEIA ${ }^{\mathrm{TM}}$ Sets 
Mouse, PharMingen, San Diego, CA). Microwell plates (96-wells, Nunc Maxisorp) were coated with capture antibody diluted (1:250) in coating buffer $(0.2$ $\mathrm{M}$ sodium phosphate, $\mathrm{pH} 6.5$ or $0.1 \mathrm{M}$ sodium carbonate, $\mathrm{pH}$ 9.5), and incubated overnight at $4{ }^{\circ} \mathrm{C}$. Wells were washed with PBS containing $0.05 \%$ Tween 20. Plates were blocked with $10 \%$ fetal bovine serum in PBS, incubated at room temperature for $1 \mathrm{~h}$, and washed with PBS. Sera (1:8) and recombinant standards were added, and plates were incubated for $2 \mathrm{~h}$ at room temperature. After washing, detection antibody plus avidin-HRP were added to each well. Plates were incubated for $1 \mathrm{~h}$ at room temperature, washed, and developed with ABTS (Zymed Laboratories, South San Francico, CA) to record the OD at $405 \mathrm{~nm}$.

\section{Statistical analysis}

Results were expressed as means \pm SD. Statistical analysis was performed using one-way ANOVA followed by Tukey's test. The survival time was calculated by the Kaplan-Meier method. Differences were considered to be statistically significant when the $p$ value was $<0.01$ or $<0.05$.

\section{Results}

\section{Immunization with rSSP4 increases para- sitemia and mortality in the murine model.}

Proliferation of spleen cells, from immunized or normal mice, stimulated in vitro with ConA or with the homologous antigen, was suppressed by the fusion protein MBP::SSP4. This suppression was inhibited by L-NAME [22], which indicates that nitric oxide is involved in suppressing spleen cells proliferation as it has been shown $[23,24]$. On the other hand, mice peritoneal macrophages (pMФs) obtained 3 and 7 days after immunization with a single dose of $M B P:: S S P 4$ showed high and null nitric oxide production respectively compared with $\mathrm{pM} \Phi \mathrm{s}$ from normal mice [22]. Therefore we investigated parasitemia and mortality in mice immunized with a single dose of the recombinant protein $r \mathrm{TCSSP} 4$ and then challenged with bloodstream trypomastigotes at 3 and 7 days post-immunization.

The recombinant protein was purified from the intein-TcSSP4 fusion protein bound to chitin beads by temperature shift. Figure 1, lane 2 shows the Coomassie blue staining of the $60 \mathrm{kDa}$ purified protein that was used to immunize the mice. To analyze whether immunization induced immunosuppression, mice were challenged with $T$. cruzi trypomastigotes. Both parasitemia and death rate were evaluated 3 and 7 days after a single immunization with $10 \mu \mathrm{g}$ of rTcSSP4. In mice challenged at both times after im- munization with $3 \times 10^{4}$ trypomastigotes, (Fig. 2A, •, $\circ)$, the parasitemia starts earlier than in normal animals (Fig. 2A, $\mathbf{\nabla}$ ). Although a peak of parasitemia was observed at day 26 in normal animals, all immunized mice died before a peak was reached. Death occurred at day 14 in those mice infected 7 days post-immunization (Fig. 2B, $\circ$ ) and at day 17 in those infected 3 days after immunization (Fig. 2B, •). Despite the peak of parasitemia shown by normal animals, they began dying at day 24 after challenge (Fig. 2B, $\boldsymbol{\nabla})$.

When the challenge dose of parasites was reduced to $1 \times 10^{4}$ (Fig. 2C and D), the beginning of parasitemia was similar in all animals and they presented the parasitemia peak at the same time. However, in immunized mice the peak was higher than in normal animals (Fig. 2C, •, ०). In spite of a higher mortality than in normal animals, the survival rate was higher $(p<0.05)$ when compared to mice infected with $3 \times 10^{4}$ trypomastigotes (Fig. $2 \mathrm{~B}$ and D), suggesting that the lower number of parasites allowed them to better control the infection process.

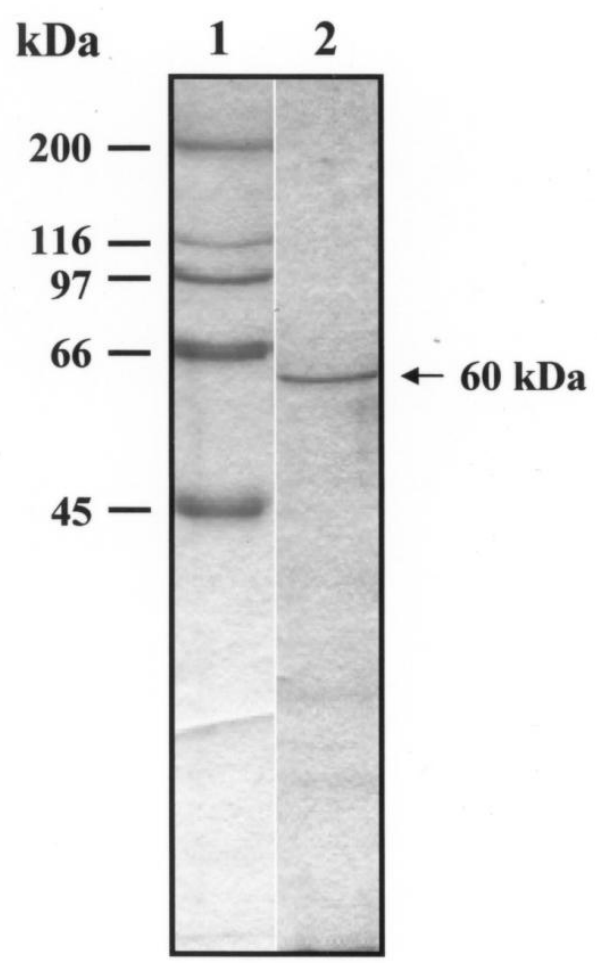

Figure I. Purification of the rTCSSP4 protein. rTcSSP4 protein was purified from the Intein-TcSSP4 fusion protein bound to chitin beads by temperature shift from $4^{\circ} \mathrm{C}$ to 25 ${ }^{\circ} \mathrm{C}$ at $\mathrm{pH}$ 7.0. (I) Molecular weight markers and (2) purified rTCSSP4. 

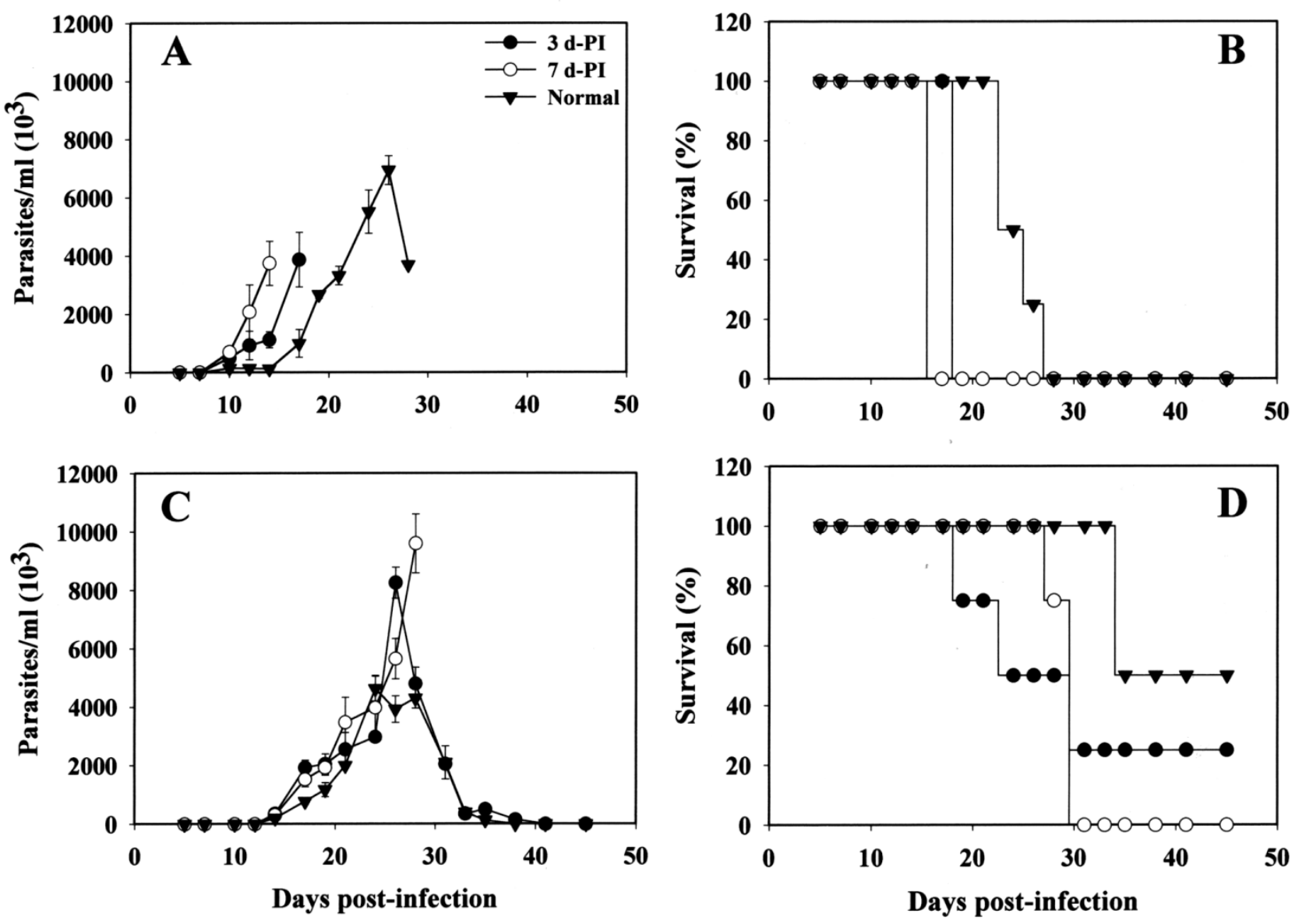

Figure 2. Parasitemia and mortality of $r T$ TSSP4 immunized mice challenged with BT. Mice were immunized with a single dose of rTcSSP4 $(10 \mu \mathrm{g})$, and at $3(\bullet)$ or $7(\circ)$ days post-immunization $(\mathrm{PI})$ animals were infected with $3 \times 10^{4}(\mathrm{~A}$ and $\mathrm{B})$ or $1 \times 10^{4}(C$ and D) BT. Parasitemia (A and C) and mortality (B and D) rates were recorded up to 45 days. Normal animals received only Freund's complete adjuvant $(\boldsymbol{\nabla})$. Parasitemia values represent mean \pm standard errors of the means for surviving mice.

\section{Intramuscular immunization with anti- gen-expressing DNA plasmid induces protec- tion against $T$. cruzi infection.}

DNA immunization is a widely used procedure. DNA codified proteins are internally processed and presented by MHC class I and II antigens, and are therefore able to induce a Th1 type immune response in which $\mathrm{CD}^{+} \mathrm{T}$ cells are activated [25]. In mice vaccinated with the plasmid pBCSSP4 and later challenged with T. cruzi parasites, the parasitemia peak was observed at day 25 with the lowest number of parasites (Fig. 3A, •), in comparison with the parasitemia peak of mice immunized with control plasmid pBk-CMV (29 days) (Fig. 3A, o), or animals injected with PBS (25 days) (Fig. 3 A, $\mathbf{\nabla}$ ). Statistically significant differences $(p<0.01)$ were found in the parasitemia peak between vaccinated and control mice. In terms of survival, the group immunized with pBCSSP4 showed the highest survival rate $(\sim 75 \%)$ even at 1 year after infection (Fig. 3B, •) $(p<0.05)$.

\section{Decreased tissue damage in mice immunized with pBCSSP4.}

Heart tissue damage was analyzed after long term infection of immunized mice. One year after initial infection, surviving animals were sacrificed. Hearts were dissected and analyzed for the presence of myocarditis and tissue damage. No damage was found in hearts from mice immunized with the plasmid pBCSSP4 (Fig. 4A). In contrast, severe myocarditis and tissue damage were observed in hearts from mice immunized with the control plasmid pBKCMV (Fig. 4B) or from mice injected with PBS (Fig. 4D). Non-immunized, non-infected mice were used as control (Fig. 4C). 

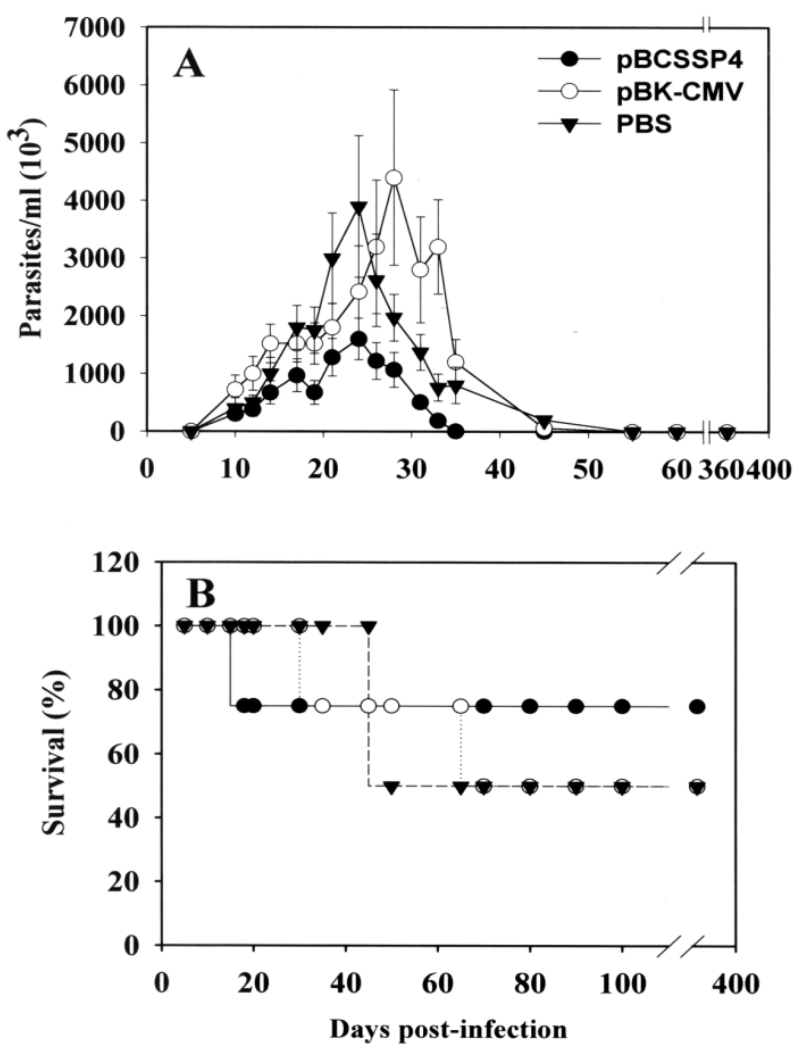

Figure 3. Parasitemia and mortality of pBCSSP4 immunized mice challenged with BT. Mice were immunized twice 15 days apart with $100 \mu \mathrm{g} /$ dose of the plasmids PBCSSP4 $(\bullet)$ and pBk-CMV (०)., Two weeks after the last immunization they were infected with $10^{4}$ BT. Control animals received only PBS $(\boldsymbol{\nabla})$. Parasitemia $(A)$ and mortality $(B)$ rates were recorded up to 365 days. Parasitemia values represent mean \pm standard errors of the means for surviving mice.
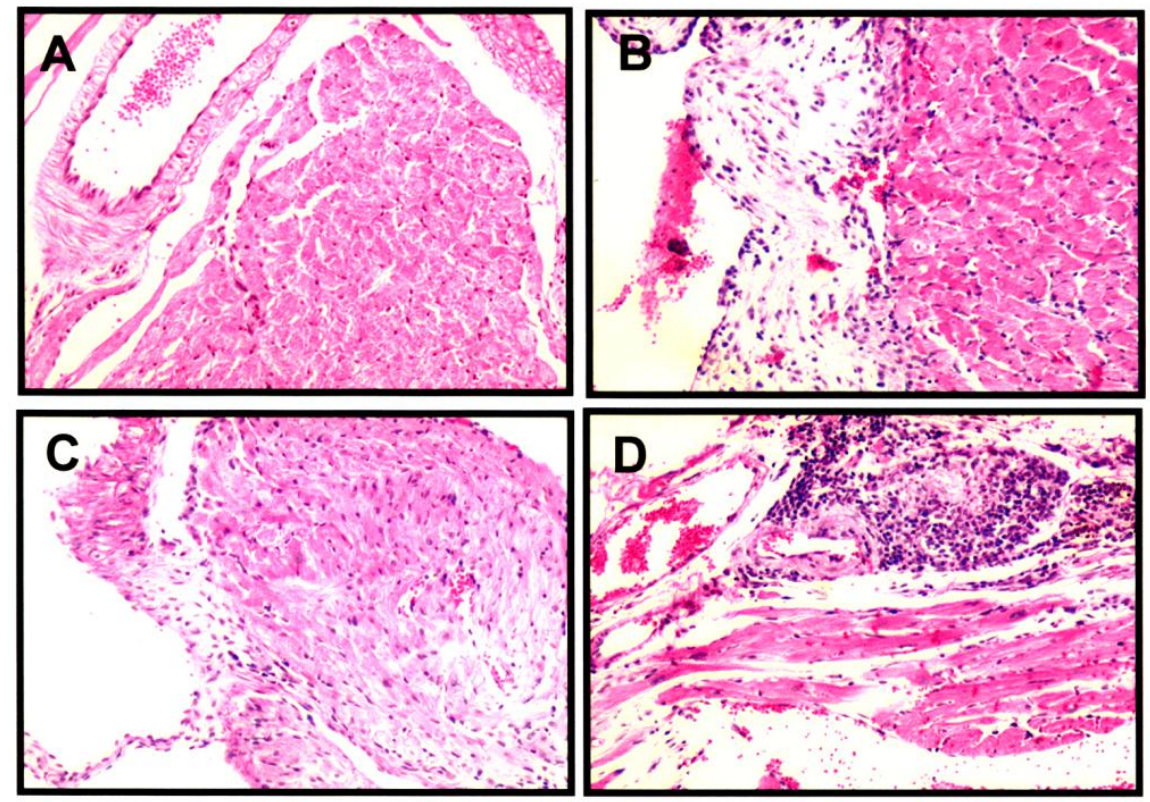

Figure 4. BALB/c mice immunized with plasmid pBCSSP4 and infected with $T$. cruzi did not develop myocarditis. BALB/c mice immunized with the plasmids PBCSSP4 (A), pBk-CMV (B), or injected with PBS (D) were infected with $10^{4} B T$. Control mice were non-immunized and non-infected (C). At 365 days post-infection, cardiac sections from corresponding mice were stained with hematoxylin and eosin. $40 \mathrm{X}$ magnification. 

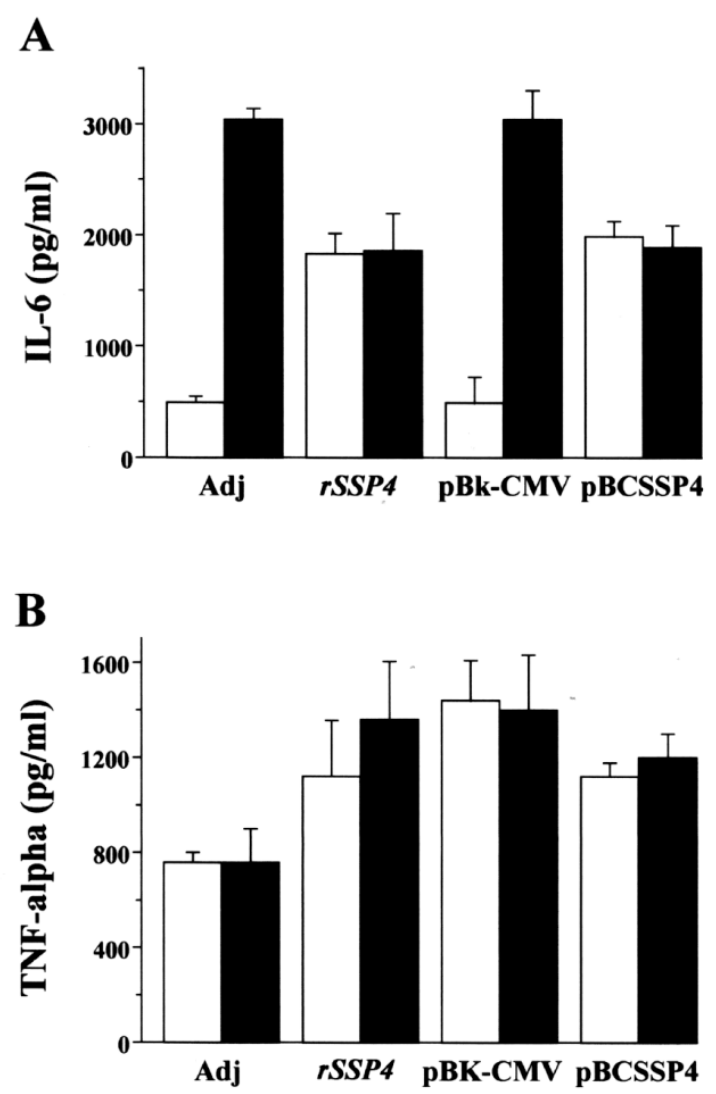

C

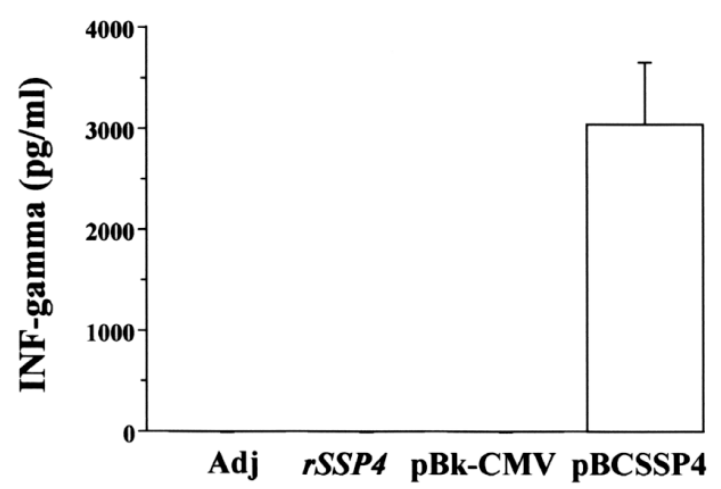

Figure 5. Serum cytokine levels in immunized mice. Pools of serum collected $3(\square)$ and 12 ( $\square$ ) h after final immunization and ELISA assays were performed for the presence of IL-6 (A), TNF- $\alpha$ (B) and IFN- $\gamma(C)$. Sera were from mice immunized twice 15 days apart, with adjuvant (Adj), rSSP4 protein $(10 \mu \mathrm{g})$, plasmid pBk-CMV $(100 \mu \mathrm{g})$, and plasmid pBCSSP4 $(100 \mu \mathrm{g})$. Values represent the mean \pm SD of a representative triplicate assay.
Serum cytokine levels in mice immunized with rTcSSP4 and pBCSSP4.

As a first approach to analyze why protein or DNA vaccinated mice died or survived respectively, the serum cytokine profile of immunized mice was analyzed. Sera from immunized and control mice were collected $3(\square)$ and $12(\mathbf{\square}) \mathrm{h}$ after the last immunization and cytokine levels were measured by ELISA. When compared with controls, statistically significant differences were found in IL-6 levels in mice immunized with either $r T c S S P 4$ protein or pBCSSP4 plasmid. The IL-6 levels were higher at $3 \mathrm{~h}$ $(p<0.01)$ and lower at $12 \mathrm{~h}(\mathrm{p}<0.01)$ (Fig. 5A). For TNF- $\alpha$, statistically significant differences were found in mice immunized with $r$ TcSSP4 protein at $3 \mathrm{~h}$ $(\mathrm{p}<0.01)$ and $12 \mathrm{~h}(\mathrm{p}<0.01)$ when compared with control mice, and no significant differences were found in mice immunized with pBCSSP4 plasmid (Fig. 5B). However, a clear difference was found regarding IFN- $\gamma$ production; only $3 \mathrm{~h}$ sera from animals immunized with the pBCSSP4 plasmid showed significant amounts of this cytokine. In $12 \mathrm{~h}$ sera this cytokine was not detected. No detectable amounts of IFN- $\gamma$ were found in the other conditions (Fig. 5C). Cytokines IL-1, IL-4, and IL-10 were not detected at these times of serum collection (data not shown).

\section{Discussion}

Mice immunized with the $r T c S S P 4$ protein and then challenged with a lethal dose of BT showed earlier parasitemia and death compared with non-immunized mice. However, when immunized animals were challenged with third of the lethal dose of parasites, parasitemia started at the same time as in non-immunized animals, but peaks of parasitemia and death rates were higher in immunized mice. These results could be explained in terms of immunossuppression and parasite load. We have previously shown that the fusion protein MBP::SSP4 was able to induce nitric oxide (NO) production by spleen and peritoneal macrophages (pM $\varphi s$ ). Also we observed that this protein suppresses spleen cell proliferation. $\mathrm{pM} \varphi s$ from normal mice as well as those that recovered 3 and 5 days after one immunization with $M B P:: S S P 4$ were able to synthesize NO, whereas $p M \varphi s$ recovered at 7 days after one immunization and 3,5 and 7 days after two immunizations were not able to produce NO. This recombinant protein was also shown to induce the expression of IL-1a, IL-6, IL-12, IFN- $\gamma$, and TNF- $\alpha$ in $p M \varphi s$ from normal mice, IL-6, TNF- $\alpha$, and IL-10 in pM $\varphi$ s recovered 3 days after one immunization, and IL- 6 and IL- 10 in pM $\varphi$ s recovered 5 days after one immunization [22]. 
Earlier parasitemia and death of mice challenged 3 days after one immunization could be due mainly to NO production induced by $r T c S S P 4$. It has been shown that NO production contributes to the immunosuppression observed during infection with Toxoplasma gondii [26], Paracoccidioides brasiliensis [27], Echinoccocus multilocularis [28], Trypanosoma brucei [29], and Trypanosoma cruzi [30]. Although NO can kill intracellular parasites, overproduction can be detrimental, even lethal, to the host $[26,31]$. In addition, earlier parasitemia and death of mice challenged 7 days after one immunization could be due to macrophage inactivation by IL-10 [32], and to the beginning of a Th2 response induced by $r T C S S P 4$. Suppression of immune responses during T. cruzi infection results in a significantly increased parasite burden [14]. Thus, immunized mice that were able to control the initial phase of parasitemia (with a lower dose of BT) showed a parasitemia peak higher than that observed in non-immunized animals. Experiments are required to follow the kinetics of the immune response development and determine the type of $\mathrm{T}$ cells that are induced (Th1 or Th2) when a full immune response has been established.

In DNA based immunization, the antigen encoded by plasmid DNA is processed in the cytoplasm by transfected cells and presented to elicit an immune response [33]. Mice immunized with the plasmid pBCSSP4, and then challenged with BT showed a reduction in parasitemia and 75\% survival, as compared with control animals. Similar results have been reported for DNA immunizations with $T$. cruzi genes, showing a reduction of parasitemia and mortality (Table 1). Besides using different genes, the variability in parasitemia and survival reported in these studies could be due to DNA doses, number of doses, interval between doses and time of challenge after the last dose, as well as parasite strain and number of parasites used to challenge. Therefore, it is necessary to develop and standardize a protocol for DNA immunization in experimental Chagas disease.

Immunization with pBCSSP4 altered the course of disease development in the chronic phase of infection in our experimental model. Immunized animals not only survived the trypomastigote infection but also showed low levels of parasitemia, and displayed undetectable levels of heart muscle inflammation and necrosis in the chronic phase of infection. Similarly, reduction in skeletal and heart muscle inflammation and necrosis in mice immunized with a mixture of plasmids containing the ASP-1, ASP-2 and TSA-1 genes and with antigen-encoding plasmids plus interleukin-12, and granulocyte-macrophage colony-stimulating factor plasmids has been reported [10].
These results support the hypothesis that severity of the disease in chronic T. cruzi infection is tightly linked to the relative success in limiting parasite levels $[14,34]$.

Table I. DNA vaccines with plasmids containing Trypanosma cruzi genes

\begin{tabular}{lll}
\hline Gene & Survival (\%) & Reference \\
TSA-1 & $55-90$ & 5 \\
CPR & 100 & 7 \\
KMP11-HSP70 & 50 & 8 \\
TS & 100 & 9 \\
ASP-1, ASP-2, TSA-1 & $30-60$ & 10 \\
Plus IL-12, GM-SF & $60-80$ & \\
Clone 9 (89.9\% identity with ASP-2) & 100 & 11 \\
CRP & 100 & 41 \\
PFR/PFR3-HSP70 & 100 & 42 \\
LYT1 Plus IL-12 & 75 & 43 \\
TS family members & 75 & 43 \\
Mucin family members & 25 & 43 \\
SSP4 & 75 & This work \\
\hline
\end{tabular}

It has been shown in the murine model that a Th1 response is able to control T. cruzi infection and to reduce the severity of the disease [35-40]. Although inflammatory cytokines IL- 6 and TNF-a were detected at $3 \mathrm{~h}$ and $12 \mathrm{~h}$ post-immunization in sera of mice immunized with adjuvant, rTcSSP4 protein, pBk-CMV, and pBCSSP4, INF- $\gamma$ was detected only at $3 \mathrm{~h}$ post-immunization in sera of mice immunized with pBCSSP4. These results suggest that mice immunized with the gene coding for the TcSSP4 protein are primed to develop a Th1 response. Experiments are being conducted, varying the number of doses of plasmid DNA and parasites, to determine the type of response just before parasite challenge.

In summary, we have shown that immunization with rTCSSP4 protein makes mice more susceptible to trypomastigote infection, and a genetic vaccine based on TcSSP4 cDNA provides partial protection against lethal infection with T. cruzi. Further investigations are needed to determine whether different DNA immunization protocols (e.g. total DNA dose, number and interval between doses, time of challenge, cytokine adjuvants) might yield better protection.

\section{Acknowledgements}

We thank Biol. Lidia Baylón Pacheco and Mr. Enrique Martínez de Luna for technical support, Mrs. Amelia Rios for manuscript revision, and Dr. Victor M. Monteon at Centro de Investigación de Enferme- 
dades Tropicales, Campeche, Campeche, México, for critical advice on histological interpretation. MAF and ARL were recipients of a Ph.D. fellowship from CONACYT, México. This work was supported by funds from Conacyt, México (grants 34991 and 47437).

\section{Conflict of Interests}

The authors have declared that no conflict of interest exists.

\section{References}

1. World Health Organization. Report of the scientific working group on chagas disease; Tech Rep. Buenos Aires, Argentina: UNDP/World Bank/WHO. 2006.

2. World Health Organization. First WHO report on neglected tropical diseases: working to overcome the global impact of neglected tropical diseases. WHO: WHO/HTM/NTD Press. 2010.

3. Moncayo A. Chagas disease: current epidemiological trends after the interruption of vectorial and transfusional transmission in the Southern Cone countries. Mem Inst Oswaldo Cruz. 2003; 98: 577-591.

4. Moncayo A, Silveira AC. Current epidemiological trends for Chagas disease in Latin America and future challenges in epidemiology, surveillance and health policy. Mem Inst Oswaldo Cruz. 2009; 104: 17-30.

5. Cazorla SI, Frank FM, Malchiodi EL. Vaccination approaches against Trypanosoma cruzi infection. Exp Rev Vacc. 2009, 8:921-35

6. Costa F, Franchin G, Pereira-Chioccola VL, et al. Immunization with a plasmid DNA containing the gene of trans-sialidase reduces Trypanosoma cruzi infection in mice. Vaccine. 1998; 16: 768-74.

7. Sepulveda P, Hontebeyrie M, Liegeard P, et al. DNA-based immunization with Trypanosoma cruzi complement regulatory protein elicits complement lytic antibodies and confers protection against Trypanosoma cruzi infection. Infect Immun. 2000; 68: 4986-91.

8. Planelles L, Thomas MC, Alonso C, et al. DNA immunization with Trypanosoma cruzi HSP70 fused to the KMP11 protein elicits a cytotoxic and humoral immune response against the antigen and leads to protection. Infect Immun. 2001; 69: 6558-63.

9. Fujimura AE, Kinoshita SS, Pereira-Chioccola VL, et al. DNA sequences encoding $\mathrm{CD}^{+}$and $\mathrm{CD}^{+} \mathrm{T}$ cell epitopes are important for efficient protective immunity induced by DNA vaccination with a Trypanosoma cruzi gene. Infect Immun. 2001; 69: 5477-86

10. Garg N, Tarleton R. Genetic immunization elicits antigen-specific protective immune responses and decreases disease severity in Trypanosoma cruzi infection. Infect Immun. 2002; 70: 5547-55.

11. Boscardin SB, Kinoshita SS, Fujimura AE, et al. Immunization with cDNA expressed by amastigotes of Trypanosoma cruzi elicits protective immune response against experimental infection. Infect Immun. 2003; 71: 2744-57.

12. Brener Z, Gazzinelli RT. Immunological control of Trypanosoma cruzi infection and pathogenesis of Chagas' disease. Int Arch Allergy Immunol. 1997; 114: 103-10.

13. Tarleton RL. Immunity to Trypanosoma cruzi. In: Kaufmann SHE, ed. Host response to intracellular pathogens. Austin: RG Landes Co.; 1997: 227-47.

14. Tarleton RL, Zhang L. Chagas' disease etiology: autoimmunity or parasite persistence?. Parasitol Today. 1999; 15: 94-9.
15. Rottenberg ME, Bakhiet M, Olsson T, et al. Differential susceptibilities of mice genomically deleted of CD4 and CD8 to infections with Trypanosoma cruzi or Trypanosoma brucei. Infect Immun. 1993; 61: 5129-33.

16. Tarleton RL, Koller BH, Latour A, et al. Susceptibility of beta 2-microglobulin-deficient mice to Trypanosoma cruzi infection. Nature. 1992; 356: 338-40.

17. Limon-Flores AY, Cervera-Cetina R, Tzec-Arjona JL, et al. Effect of a combination DNA vaccine for the prevention and therapy of Trypanosoma cruzi infection in mice: role of CD4+ and CD8+ T cells. Vaccine. 2010; 28: 7414-19.

18. Miyahira Y, Takashima Y, Kobayashi S, et al. Immune responses against a single CD8+-T-cell epitope induced by virus vector vaccination can successfully control Trypanosoma cruzi infection. Infect Immun. 2005; 73: 7356-65.

19. Araujo AF, de Alencar BC, Vasconcelos JR, et al. CD8+-T-cell-dependent control of Trypanosoma cruzi infection in a highly susceptible mouse strain after immunization with recombinant proteins based on amastigote surface protein 2 . Infect Immun. 2005; 73: 6017-25.

20. Martin DL, Weatherly DB, Laucella SA, et al. CD8+ T-cell responses to Trypanosoma cruzi are highly focused on strain-variant trans-sialidase epitopes. PLoS Pathog 2006; 2: e77.

21. Padilla AM, Bustamante JM, Tarleton RL. CD8+ T cells in Trypanosoma cruzi infection. Curr Opin Immunol. 2009; 21: 385-90.

22. Ramos-Ligonio A, López-Monteon A, Talamás-Rohana P, et al. Recombinant Ssp-4 protein from Trypanosoma cruzi amastigotes regulates Nitric Oxide production by macrophages. Parasite Immunol. 2004; 26: 409-18.

23. Abrahamson I, Coffman R. Cytokine and nitric oxide regulation of the immunosuppression in Trypanosoma cruzi infection. J Immunol. 1995; 155: 3955-61.

24. Gutierrez Fredy RS, Mineo Tiago WP, Pavanelli Wander R, Guedes Paulo MM, Silva João S. The effects of nitric oxide on the immune system during Trypanosoma cruzi infection. Mem Inst Oswaldo Cruz. 2009; 104 (Suppl. I): 236-245.

25. Gurunathan S, Klinman DM, Seder RA. DNA vaccines: Immunology, application and optimization. Annnu Rev Immunol. 2000; 18: 927-74.

26. Khan IA, Schwartzman JD, Matsuura T, et al. A dichotomous role for nitric oxide during acute Toxoplasma gondii infection in mice. Proc Natl Acad Sci. 1997; 94: 13955-60.

27. Bocca AL, Hayashi EE, Pinheiro AG, et al. Treatment of Paracoccidioides brasiliensis-infected mice with a nitric oxide inhibitor prevents the failure of cell-mediated immune response. J Immunol. 1998; 161: 3056-63.

28. Dai WJ, Gottstein B. Nitric oxide-mediated immunosuppression following murine Echinococcus multilocularis infection. Immunology. 1999; 97: 107-16.

29. Stenberg J, McGuigan F. Nitric oxide mediates suppression of $T$ cell response in murine Trypanosoma brucei infection. Eur J Immunol. 1992; 22: 2741-44.

30. Abrahamson I, Coffman R. Cytokine and nitric oxide regulation of the immunosuppression in Trypanosoma cruzi infection. J Immunol. 1995; 155: 3955-61.

31. Nascimento FR, Calich VL, Rodriguez D, et al. Dual role for nitric oxide in paracoccidioidomycosis: essential for resistance, but overproduction associated with susceptibility. J Immunol 2002; 168: 4593-600.

32. O'Farrell AM, Liu Y, Moore KW, et al. IL-10 inhibits macrophage activation and proliferation by distinct signaling mechanism: evidence for Stat-3-dependent and -independent pathways. EMBO J. 1998; 17: 1006-18.

33. Gurunathan S, Klinman DM, Seder RA. DNA Vaccines: Immunology, application and optimization. Ann Rev Immunol. 2000; 18: 927-74. 
34. Tarleton RL. Parasite persistence in the aetiology of Chagas disease. Int J Parasitol. 2001; 31: 550-4.

35. Araujo F. Development of resistance to Trypanosoma cruzi in mice depends on a viable population of L3T41 (CD41) T lymphocytes. Infect Immun. 1989; 57: 2246-8.

36. McCabe R, Meagher S, Mullins B. Gamma interferon suppresses acute and chronic Trypanosoma cruzi infection in cyclosporin-treated mice. Infect Immun. 1991; 59: 1633- 8.

37. Minoprio P, el Cheikh MC, Murphy E, et al. Xid-associated resistance to experimental Chagas disease is IFN-gamma dependent. J Immunol. 1993; 151: 4200-8.

38. Rottenberg ME, Riarte A, Sporrong L, et al. Outcome of infection with different strains of Trypanosoma cruzi in mice lacking CD4 and/or CD8. Immunol Lett. 1995; 45: 53-60.

39. Hoft DF, Schnapp AR, Eickhoff CS, et al. Involvement of CD4+ Th1 cells in systemic immunity protective against primary and secondary challenges with Trypanosoma cruzi. Infect Immun. 2000; 68: 197-204.

40. Hoft DF, Eickhoff CS. Type 1 immunity provides optimal protection against both mucosal and systemic Trypanosoma cruzi challenges. Infect Immun. 2002; 70: 6715-25.

41. Sepulveda P, Hontebeyrie M, Liegeard P, Mascilli A, Norris KA. DNA-Based immunization with Trypanosoma cruzi complement regulatory protein elicits complement lytic antibodies and confers protection against Trypanosoma cruzi infection. Infec Immun. 2000; 68: 4986-91.

42. Morell M, Thomas MCC, Caballero T, Alonso C, Lopez MC. The genetic immunization with paraflagellar rod protein-2 fused to the HSP70 confers protection against late Trypanosome cruzi infection. Vaccine. 2006; 24: 7046-55.

43. Fralish BH, Tarleton RL. Genetic immunization with LYT1 or a pool of trans-sialidase genes protects mice from lethal Trypanosoma cruzi infection. Vaccine. 2003; 21: 3070-80. 